Vietnam Journal of Mechanics, NCST of Vietnam Vol. 21, 1999, No 2, (99-115)

\title{
AN ALGORITHM FOR SIMULTANEOUS DETERMINATION OF PRESSURE AND TEMPERATURE DISTRIBUTION IN OIL-PRODUCING TUBE FLOW AND THE COUNTER FLOW IN GAS-LIFT ANNULUS
}

\author{
By Ha NGOC HIEN*, NGUYEN VAN DIEP*, \\ DUONG NGOC HaI*, NGUYen Van CanH** \\ * Institute of Mechanics, NCST of Vietnam \\ ** Institute of Offshore Oil-Gas Research Design, JV Vietsovpetro.
}

\begin{abstract}
An algorithm for simultaneous determination of pressure and temperature distribution in oil-producing tube flow and the counter flow in gas-lift annulus has been proposed. The algorithm is based on a double loop iterative procedure and shooting method. The two-phase flow calculation for pressure used in the algorithm is based on improved methods of Beggs and Brills, Orkizzewski or Hagedorn and Brown. The numerical implementation for an example is presented to assure the applicability of proposed algorithm.
\end{abstract}

\section{Introduction}

The problem of accurately predicting pressure drops in oil-producing well has been developed in the last 50 years. In general, heat transfer calculations were not been considered, and the temperature distribution was usually assumed to be linear between the surface temperature and bottom hole temperature. In many cases this assumption will not introduce significant errors. Nevertheless, the heat transfer calculations can be very important when the liquid rate of a well is changed, in gas-lift-injection wells, flow of high paraffin oil, etc.

Various algorithms for coupling pressure and heat losses calculation in oilproducing well were presented in $[1,2]$. These algorithms have been performed without considering the case of counter flow of gas in gas-lift annulus.

This paper presents an algorithm for simultaneous calculation of pressure and heat losses in oil-producing tube as well as in gas-lift annulus. Assuming the liquid production rate and gas injection rate are known, the pressure and temperature 
distributions in the producing tube and gas-lift annulus can be determined if a given set of boundary conditions is sufficient, i.e. the set of conditions on the surface or in the reservoir. For example, the well-head pressure, well-bottom temperature, injection depth and the surface temperature of injection gas make a sufficient set of boundary conditions. In this case, the most important quantities need to be determined are the well-bottom pressure, well-head temperature, surface injection pressure, and the temperature and pressure at the injection point, i.e. at the injection valve.

At first, the basic equations that describe the flow and heat exchange in producing tube and in the gas-lift annulus are presented, and the boundary conditions will be discussed. The effects of the phase transition such as paraffin crystallisation and vaporisation are taken into account in the pressure equations as well as in the temperature equations.

Next, the algorithm for one case of the boundary conditions will be presented. Some known methods such as Beggs and Brills method[1, 3], Orkiszewski method[1, 4], and Hagerdorn and Brown[1] method are improved and used in the algorithm for solution of two-phase flow equations in the producing tube.

At the end, some results of calculation for one producing well are presented and conclusions are given.

\section{Basic equations and boundary conditions}

Figure 1 presents a schematic diagram of producing well with gas-lift injection.

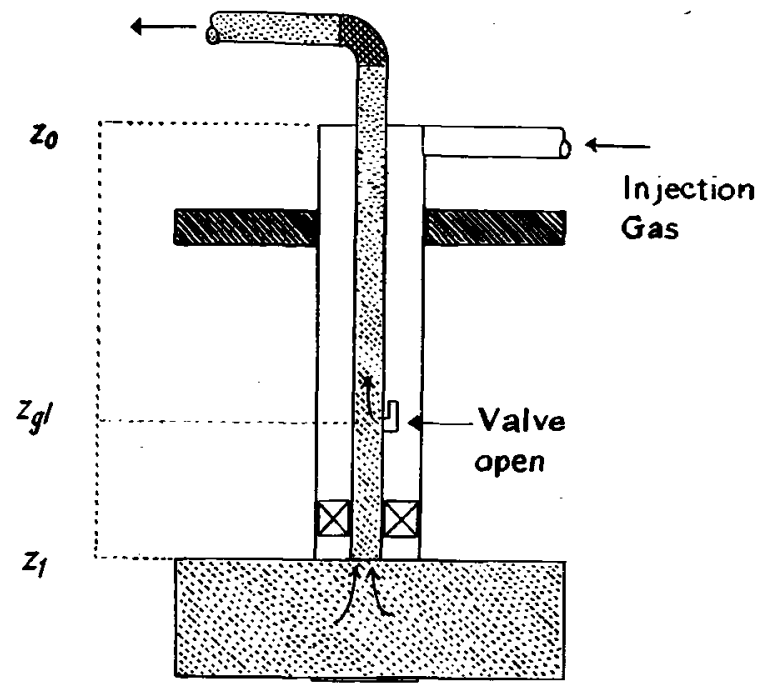

Fig. 1. Schematic diagram of a oil-producing well

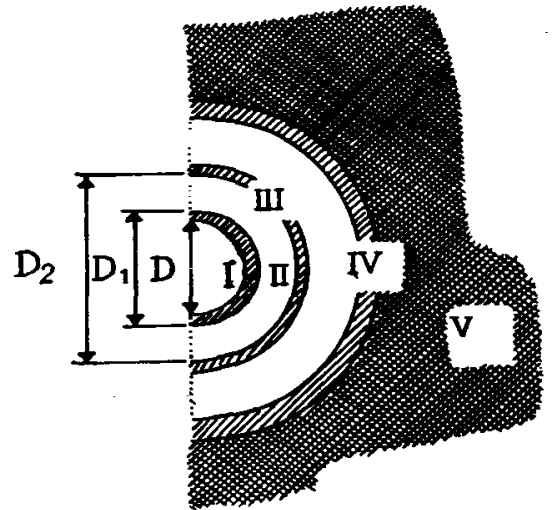

I. Producing tube

IV. Second casing

II. Gas-lift annulus

V. Ground

III. First casing

Fig. 2. Well cross-section 
Gas is continuously injected into tube through a gas-lift valve at a fixed depth $z_{\rho \ell}$. The injected gas is conducted to the valve through an annulus, which is modelled by equivalent circular pipe with hydraulic and thermal equivalent diameters. The flow in the producing tube is a multi-phase flow and the gas-liquid ratio is increased from the valve to the surface.

Under the steady conditions, the equations for pressure and temperature calculation in producing tube and in gas-lift annulus can be written as presented below.

\subsection{Pressure and temperature equations in producing tube}

\section{a. Pressure equation}

The total pressure gradient of fluid flowing in a pipe inclined at a given angle $\theta$ from horizontal, can be considered to be composed of three distinct components, that is $[1]$ :

$$
\frac{d p_{0}}{d z}=\left(\frac{d p_{0}}{d z}\right)_{e l}+\left(\frac{d p_{0}}{d z}\right)_{f}+\left(\frac{d p_{0}}{d z}\right)_{a c c}
$$

where $\left(\frac{d p_{0}}{d z}\right)_{e l}=g \rho_{t p} \sin \theta$ is the component due to potential energy or elevation change (hydrostatic component); $\left(\frac{d p_{0}}{d z}\right)_{f}=\frac{f_{t p} \rho_{f} v_{m f}^{2}}{2 D} f_{c o r r}$ is the component due to friction losses. $\left(\frac{d p_{0}}{d z}\right)_{a c c}=\frac{\rho v d v}{d z}$ is the component due to kinetic energy change or convective acceleration (This component is negligible for most practical cases). And under several simplifying assumptions it can be expressed as following[3], [4]:

$$
\left(\frac{d p_{0}}{d z}\right)_{a c c}=-\frac{\rho_{t p} v_{m} v_{s g}}{p_{0}} \frac{d p_{0}}{d z}
$$

The quantities $\rho_{t p}, p_{f}, v_{m f}$ and $f_{\text {corr }}$ are determined dependently by flow pattern and method of calculations (see Appendix A).

b. Temperature equation

The total temperature gradient in producing tube can be considered to be composed of five distinct components, that is [2]:

$$
\frac{d t_{0}}{d z}=\left(\frac{d t_{0}}{d z}\right)_{p}+\left(\frac{d t_{0}}{d z}\right)_{e x}+\left(\frac{d t_{0}}{d z}\right)_{L g}+\left(\frac{d t_{0}}{d z}\right)_{L f}+\left(\frac{d t_{0}}{d z}\right)_{f}
$$

where

$$
\left(\frac{d t_{0}}{d z}\right)_{p}=\frac{\left[\alpha_{p} \lambda_{L} T_{0}+\left(1-\lambda_{L}\right)\left(1+\eta_{p} T_{0}\right)\right]}{c_{p w} \rho_{n}} \frac{d p_{0}}{d z}
$$


is the component due to expansion of the gas and the liquid.

$$
\left(\frac{d t_{0}}{d z}\right)_{e x}=\frac{\pi D k_{\tau}}{w_{t} c_{p w}}\left(t_{0}-t_{e x}\right)
$$

is the heat loss to surroundings;

$$
\begin{gathered}
t_{e x}= \begin{cases}t_{g} & \text { for } z<z_{g l} \\
t_{g r} & \text { for } z \geq z_{g l}\end{cases} \\
\left(\frac{d t_{0}}{d z}\right)_{L g}=-L_{g} \frac{d}{d z}\left(\frac{\left(1-\lambda_{L}\right) \rho_{g}}{c_{p w} \rho_{n}}\right)
\end{gathered}
$$

is the component due to vaporisation.

$$
\left(\frac{d t_{0}}{d z}\right)_{L f}=L_{f} \frac{d}{d z}\left(\frac{\lambda_{L} \varepsilon_{p}}{c_{p w} \rho_{n}}\right)
$$

is the component due to paraffin crystallisation.

$$
\left(\frac{d t_{0}}{d z}\right)_{f}=\frac{f_{t p} w_{t} v_{m}}{2 D C c_{p w} \rho_{n}}
$$

is the component concerned friction losses.

$k_{r}$ is the overall heat transfer coefficient, which can be determined as presented in Appendix B.

\subsection{Pressure and temperature equations in gas-lift annulus}

The flow of gas in the gas-lift annulus can be modelled by flow of gas in a circular pipe with a hydrodynamic equivalent diameter used for calculation of the friction component and with a thermal equivalent diameter used for calculation of overall heat transfer coefficient. According to these assumptions, the equations for pressure and temperature in the gas-lift annulus can be written as following [2]:

a. Pressure equation

$$
w^{2} \frac{1+\eta_{p} T_{g}}{T_{g}} \frac{d t_{g}}{d z}+\left(\frac{1}{\rho_{g}}-w^{2} \frac{1-\xi_{T}}{P_{g}}\right) \frac{d p_{g}}{d z}=f_{g} \frac{w^{2}}{2\left(D_{2}-D_{1}\right)}+g \sin \theta
$$

b. Temperature equation

$$
c_{p g} \rho_{g} \frac{d t_{g}}{d z}-\left(1+\eta_{T} T_{g}\right) \frac{d p_{g}}{d z}=-\frac{\pi D_{2} \rho_{g} k_{\tau g}}{G_{g}}\left(t_{g}-t_{g r}\right)-\frac{\pi D \rho_{g} k_{\tau}}{G_{g}}\left(t_{g}-t_{0}\right)+f_{g} \frac{\rho_{g} w^{2}}{2\left(D_{2}-D_{1}\right)}
$$


where

$$
\rho_{g}=\frac{M p_{g}}{848 z_{g} T_{g}}, \quad w=\frac{4 G_{g}}{\pi\left(D_{2}^{2}-D_{1}^{2}\right) \rho_{g}}, \quad \eta_{p}=\frac{1}{z_{g}}\left(\frac{\partial z_{g}}{\partial T}\right), \quad \xi_{T}=\frac{1}{z_{g}}\left(\frac{\partial z_{g}}{\partial p}\right)_{r} .
$$

The equivalent diameters for determination of $f_{g}$ and $k_{r,}$ are:

$$
D_{\text {heq }}=D_{2}-D_{1}
$$

and

$$
D_{t e q}=\frac{D_{2}^{2}-D_{1}^{2}}{2 D_{2}}
$$

respectively.

The determination of overall heat transfer coefficient $k_{\tau_{e}}$ is presented in Appendix $B$.

\subsection{Conditions at gas-lift valve}

In steady condition a valve can be considered as a pipe with three equivalent parameters: the equivalent length $L_{e q}$; the equivalent diameter $D_{e q}$ and the equivalent cross-section area $A_{\text {eq }}$.

The pressure difference between the annulus and producing tube at injection point can be calculated according to following expression:

$$
\Delta p=-f_{g} \frac{\rho_{g} w^{2}}{2 D_{e q}} L_{e q}
$$

where $w=\frac{G_{g}}{A_{\text {eq }} \rho_{g}}$.

The temperature of flowing liquid in the tube at the injection point may be considered as discontinuous and can be determined by the relation:

$$
t_{0^{+}}=\frac{t_{0^{-}} c_{p w} w_{t}+t_{g} c_{p g} G_{g}}{c_{p w} w_{t}+c_{p g} G_{g}}
$$

where $t_{0^{+}}$and $t_{0^{-}}$are the temperatures of the fluid above and under the valve respectively.

\subsection{Boundary conditions}

Assuming the producing liquid rate and gas injection rate are known, the sufficient boundary conditions for determination of pressure and temperature distribution in producing tube and in gas-lift annulus can be formulated as following: 
- for the producing tube: pressure and temperature either at the inlet or at the outlet of the tube must be required. It is not necessary that pressure and temperature must be known at the same end of the tube. There are, therefore, four possibilities of boundary conditions for this case:

1. Pressure and temperature are known at the top (outlet) of producing tube

2. Pressure and temperature are known at the bottom (inlet) of producing tube

3. Pressure at the top (outlet) and temperature at the bottom (inlet) of producing tube are known

4. Pressure at the bottom (inlet) and temperature at the top (outlet) of producing tube are known

- for gas-lift annulus: the temperature of injected gas at the surface must be required. Since the gas injection rate and the characteristic parameters of valve are given, the pressure of injected gas at the surface is, therefore, dependent on the position of the valve. If the pressure at surface is known then the position of the valve can be determined, and in reverse, if the position of valve is given then the pressure at surface can be determined. For the gas-lift annulus are, therefore, two possibilities:

1. The temperature and pressure of injected gas at surface are given

2. The temperature of injected gas at surface and position of the valve are given

The combination of the conditions for the producing tube and for gas-lift annulus makes eight sets of sufficient boundary conditions, which is summarised in the Table 1.

Table 1. Eight sets of boundary conditions

\begin{tabular}{|c|c|c|c|c|c|c|c|}
\hline \multirow{3}{*}{$\begin{array}{c}\text { Set } \\
\text { number }\end{array}$} & \multicolumn{4}{|c|}{ Producing tube } & \multicolumn{3}{|c|}{ Gas-lift annulus } \\
\hline & \multicolumn{2}{|c|}{ at Top } & \multicolumn{2}{|c|}{ at Bottom } & \multicolumn{2}{|c|}{ at Surface } & \multirow{2}{*}{$\begin{array}{l}\text { Valve } \\
\text { position }\end{array}$} \\
\hline & temp. & press. & temp. & press. & temp. & press. & \\
\hline 1 & & known & known & & known & & known \\
\hline 2 & & known & known & & known & known & \\
\hline 3 & known & known & & & known & & known \\
\hline 4 & known & known & & & known & known & \\
\hline 5 & known & & & known & known & & known \\
\hline 6 & known & & & known & known & known & \\
\hline 7 & & & known & known & known & & known \\
\hline 8 & & & known & known & known & known & \\
\hline
\end{tabular}


In practice, the condition of imposing the temperature at the top of producing tube is very sensible condition. That means a little change in the temperature in the top causes a magnifical change of temperature at the bottom. Otherwise, the temperature at the top is strongly dependent on the liquid rate, so the condition of imposing this temperature is not commonly advised. Hence, the boundary conditions set 3-6 can be rejected from consideration.

The remained problems with the boundary conditions set $1,2,7$ or 8 have practical meanings and are worth for consideration.

Now the procedure for solution of the problem with the boundary conditions 1 will be presented below. The problems with the sets 2,7 or 8 may be treated similarly.

\section{Procedure of solution}

\subsection{Mathematical formulation}

The considered problem can be written in the form of a system of non-linear ordinary differential equations as following:

$$
\left.\begin{array}{l}
\frac{d p_{0}}{d z}=F_{p_{0}}\left(t_{0}, p_{0}\right) \\
\frac{d t_{0}}{d z}=F_{t_{0}}\left(t_{0}, p_{0}, t_{g}, \frac{d p_{0}}{d z}\right) \\
\frac{d p_{g}}{d z}=F_{p_{g}}\left(t_{g}, p_{g}, \frac{d t_{g}}{d z}\right) \\
\frac{d t_{g}}{d z}=F_{t_{g}}\left(t_{g}, p_{g}, \frac{d p_{g}}{d z}, t_{0}\right)
\end{array}\right\} \text { for } z_{0}<z<z_{\ell}
$$

with the boundary conditions:

$$
\begin{aligned}
p_{0}\left(z_{0}\right) & =p_{0 z 0} \\
t_{0}\left(z_{\ell}\right) & =t_{0 z \ell} \\
t_{g}\left(z_{0}\right) & =t_{0 z 0}
\end{aligned}
$$

and the condition at injection point $z=z_{g \ell}$

$$
\begin{array}{r}
p_{g}-p_{0}=F_{v a l}\left(t_{g}, p_{g}, p_{0}\right) \\
t_{0^{+}}=\frac{t_{0}-c_{p w} w_{t}+t_{g} c_{p g} G_{g}}{c_{p w} w_{t}+c_{p g} G_{g}}
\end{array}
$$

where $F_{p_{0}}, F_{t_{0}}, F_{p_{g}}, F_{t_{g}}$ and $F_{v a l}$ are no-linear functions determined by (2.1), (2.2), (2.3), (2.4) and (2.8) respectively. 


\subsection{Finite difference formulation}

Dicretize the $\mathrm{z}$ variable by $z_{0}, z_{1}, \ldots, z_{n}$ such that $z_{0}=z_{0}, z_{n}=z_{\ell}$ and $\Delta z=z_{i+1}-z_{i}$ for $i=0,1, \ldots, n-1$.

An approximation to the function $\theta$ at the point $z_{i}$ will be denoted by:

$$
\theta_{i}=\theta\left(z_{i}\right) \text { and } \theta_{i+1 / 2}=\frac{1}{2}\left(\theta_{i+1}+\theta_{i}\right)
$$

The equations (3.1)-(3.2) approximated implicitly by backward Euler approximations will get the form:

$$
\begin{aligned}
& \frac{p_{0 i+1}-p_{0 i}}{\Delta z}=F_{p_{0}}\left(t_{0 i+1 / 2}, p_{0 i+1 / 2}\right) \\
& \frac{t_{0 i+1}-t_{0 i}}{\Delta z}=F_{t_{0}}\left(t_{0 i+1 / 2}, p_{0 i+1 / 2}, t_{g i+1 / 2}, \frac{p_{0 i+1}-p_{0 i}}{\Delta z}\right) \\
& \frac{p_{g i+1}-p_{g i}}{\Delta z}=F_{p_{0}}\left(t_{g i+1 / 2}, p_{g i+1 / 2}, \frac{t_{g i+1}-t_{g i}}{\Delta z}\right) \\
& \frac{t_{g i+1}-t_{g i}}{\Delta z}=F_{t_{o}}\left(t_{g i+1 / 2}, p_{g i+1 / 2}, \frac{P_{g i+1}-p_{g i}}{\Delta z}, t_{0 i+1 / 2}\right)
\end{aligned}
$$

The finite difference equations (3.6)-(3.9) are strongly non-linear. And an iterative procedure will be used for solving this system of non-linear equations.

\subsection{The iterative procedure}

The iterative procedure with double loop is used for solving the system of nonlinear finite difference equations (3.6)-(3.9). The inner loop is used for pressure calculations (with the iterative index $\ell$ ), and the outer loop is used for temperature calculations (with the iterative index $k$ ).

Assuming the values of temperature and pressure are known in $k$-th iterative step at point $z_{i+1}$, that means the values $p_{0 i+1}^{(k)}, t_{0 i+1}^{(k)}, p_{g i+1}^{(k)}, t_{g i+1}^{(k)}$ are known. The inner iterative loop with index $\ell$ allows to determine the pressure values in the following way:

Set $p_{0 i+1}^{k, 0}=p_{0 i+1}^{(k)}, p_{g i+1}^{k, 0}=p_{g i+1}^{(k)}$. The values of pressure in $\ell+1$-th iterative step are obtained from the equations:

$$
\begin{aligned}
& p_{0 i+1}^{k, \ell+1}=p_{0 i}+\Delta z F_{p_{0}}\left(t_{0 i+1 / 2}^{(k)}, p_{o i+1 / 2}^{k, \ell}\right), \\
& p_{g i+1}^{k, j+1}=p_{g i}+\Delta z F_{p_{g}}\left(t_{g i+1 / 2}^{(k)}, p_{g i+1 / 2}^{k, \ell}, \frac{t_{g i+1}^{(k)}-t_{g i}^{(k)}}{\Delta z}\right) .
\end{aligned}
$$

The convergence of this loop gives the values: $\bar{p}_{0 i+1}^{(k)}$ and $\bar{p}_{g i+1}^{(k)}$, which will be used for the outer loop. 
Similarly, for the outer loop, the values of temperature in the $k+1$-th step can be calculated from the equations:

$$
\begin{aligned}
& t_{0 i+1}^{(k+1)}=t_{0 i}+\Delta z F_{t_{0}}\left(t_{0 i+1 / 2} ; \bar{p}_{0 i+1 / 2}^{(k)}, t_{g i+1 / 2}^{(k)}, \frac{\bar{p}_{0 i+1}^{(k)}-p_{0 i}}{\Delta z}\right) \\
& t_{g i+1}^{(k+1)}=t_{g i}+\Delta z F_{t_{g}}\left(t_{g i+1 / 2}^{(k)}, \bar{p}_{g i+1 / 2}^{(k)} \frac{\bar{p}_{g i+1}^{(k)}-p_{g i}}{\Delta z}, t_{0 i+1 / 2}^{(k)}\right) .
\end{aligned}
$$

The convergence of this loop gives the solution at point $z_{i+1}$ :

$$
\begin{array}{ll}
p_{0 i+1}=\bar{p}_{0 i+1}^{(k)}, & p_{g i+1}=\dot{p}_{g i+1}^{(k)} \\
t_{0 i+1}=t_{0 i+1}^{(k+1)}, & t_{g i+1}=t_{g i+1}^{(k+1)}
\end{array}
$$

\subsection{Using the shooting method}

The iterative algorithm described above uses the values of point $z_{i}$ to calculate the values of point $z_{i+1}$. While the boundary conditions sets 1,2 or 7,8 do not give the conditions at the same point (at the top or bottom of the tube). Some boundary conditions are, therefore, to be assumed to start the calculation loops, and the shooting method has to be used for getting the given boundary conditions. For the boundary conditions set 2 , the temperature on the top of producing tube and the injection pressure at the surface are to be assumed, then the temperature at bottom of producing tube and the position of the gas-lift valve can be determined. And an iterative procedure like the shooting method [6] will be used for matching the given temperature at bottom and given position of the valve.

\section{Example of calculation}

The algorithm described above is realized in a computer program and applied for one producing well with gas-lift injection. The main characteristic parameters of the well are given below:

Oil rate :

Gas rate:

Gas injection rate:

Depth of gas-lift valve:

Pressure at top of producing tube:

Temperature of liquid at bottom:

Temperature of injected gas at surface:

Length of producing tube:

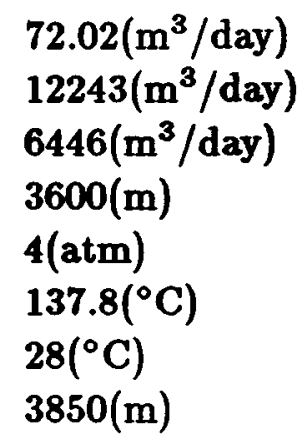


The results of calculation are presented in figure 3. The calculated values at boundaries are good in comparison with the measured data:

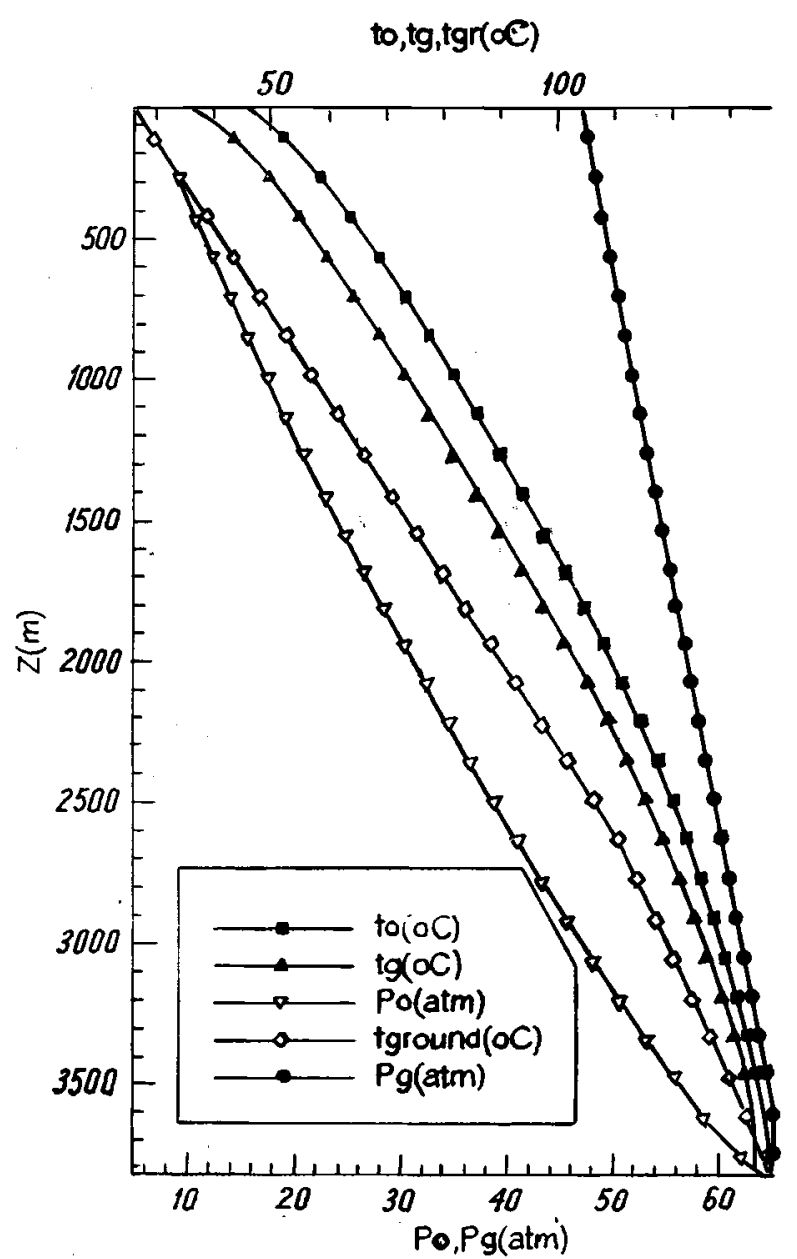

Fig. 3. Pressure and temperature distributions of the tube and annulus

$\begin{array}{llll} & \text { Measured } & \text { Calculated } & \text { Error }(\%) \\ \text { Pressure at bottom of prod. tube }(\mathrm{atm}) & 66.64 & 63.2 & 5.16 \\ \text { Temp. at top of prod. tube }\left({ }^{\circ} \mathrm{C}\right) & 39 & 42.57 & -9.15\end{array}$

The pressure and temperature at which the gas-lift valve is operating can be determined:

Temp. at operating gas-lift valve

$$
\begin{array}{r}
134.4\left({ }^{\circ} \mathrm{C}\right) \\
65.03(\mathrm{~atm})
\end{array}
$$

Press. at operating gas-lift valve $65.03(\mathrm{~atm})$

This information is important for gas-lift design of the well.

The computer program allows to analyse the contributions of each component in pressure equation (2.1), and the temperature equation (2.2) at each point of 
the producing tube. The contributions of components change significally along the tube. And it can be seen in the figure 4 and 5

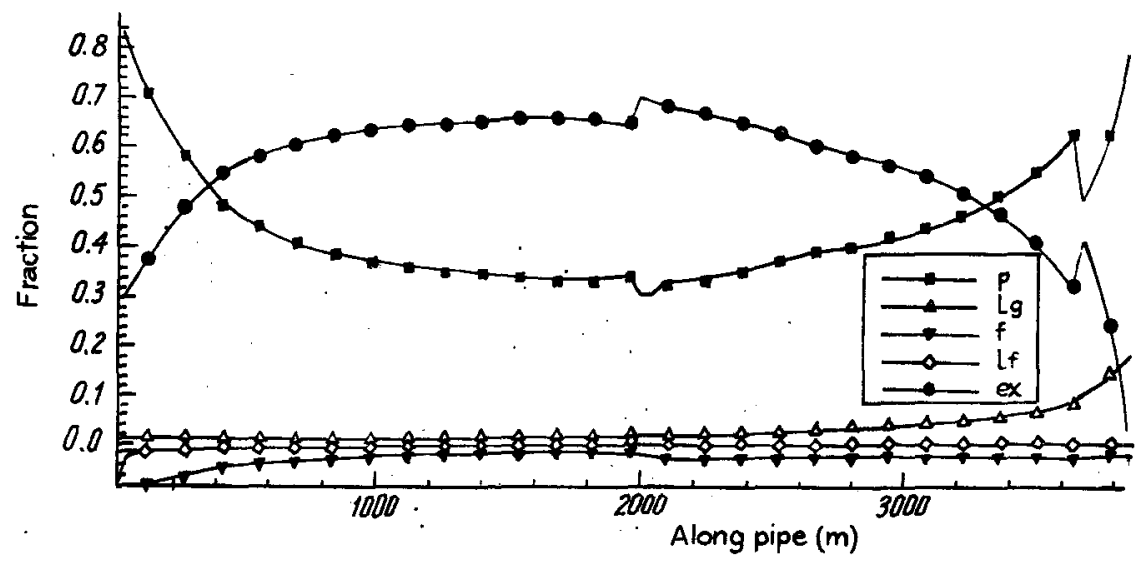

Fig. 4. Component fraction of total temperature change

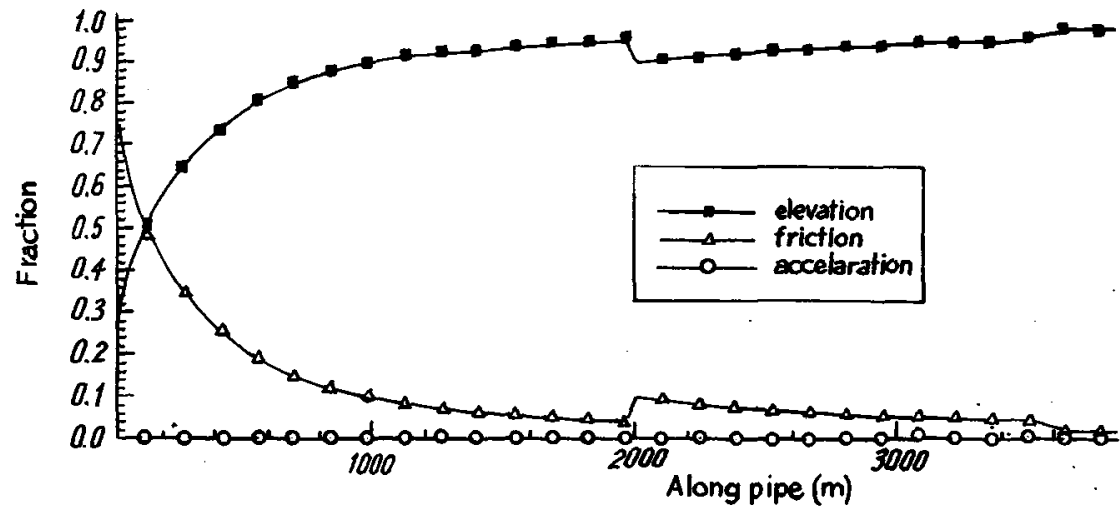

Fig. 5. Component fraction of total pressure change

\section{Conclusion}

The algorithm for solving simultaneously the system of equations governing the hydrodynamic and thermal processes in producing tube and gas-lift annulus was presented. The algorithm was based on double loop iterative procedure to solve the system of non-linear finite difference equations. An iterative procedure based on shooting method was been also used for the case of complicated boundary conditions.

The algorithm was implemented by a computer program on $\mathrm{PC}$, and the results of calculations of an example show that it can be used for multi-purposes analysis of oil producing well. 
This publication is partly completed with financial support from the National Basic Research Program in Natural Sciences.

\section{Nomenclature}

\begin{tabular}{|c|c|c|}
\hline$A$ & area & $\mathrm{m}^{2}$ \\
\hline$c_{p}$ & specific heat & $\mathrm{j} / \mathrm{kg}$ \\
\hline$c_{w p}$ & effective specific heat of flowing fluid in tube & $\mathbf{J} / \mathbf{k g}$ \\
\hline$c_{p g}$ & specific heat of injected gas & $\mathbf{J} / \mathbf{k g}$ \\
\hline$D$ & inner diameter of proc. tube & $\mathrm{m}$ \\
\hline$D_{1}$ & outer diameter of proc. tube & $\mathbf{m}$ \\
\hline$D_{2}$ & inner diameter of first casing & $\mathbf{m}$ \\
\hline$f_{n}$ & friction factor & \\
\hline 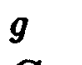 & acceleration of gravity & $\mathrm{m} / \mathrm{sec}^{2}$ \\
\hline$G_{g}$ & mass rate of injected gas & $\mathrm{kg} / \mathrm{m}^{3}$ \\
\hline$H_{L}$ & liquid holdup & \\
\hline$k_{\tau}$ & overall heat transfer coeff. for producing tube & $w / m^{\circ} \mathrm{C}$ \\
\hline$k_{\tau_{g}}$ & overall heat transfer coeff. for gas-lift annulus & $w / m^{\circ} \mathrm{C}$ \\
\hline$L_{g}$ & latent heat of vaporisation & $\mathbf{J} / \mathbf{k g}$ \\
\hline$L_{f}$ & latent heat of paraffin crystallisation & $\mathbf{J} / \mathbf{k g}$ \\
\hline$M$ & molecule weight & $\mathrm{kg}$ \\
\hline & pressure & Pas \\
\hline$p_{0}$ & pressure of iquid in proc. tube & Pas \\
\hline$g$ & pressure of injected gas. & Pas \\
\hline$g$ & gas volumetric rate & $\mathrm{m}^{3} / \mathrm{sec}$ \\
\hline 70 & oil volumetric rate & $\mathrm{m}^{3} / \mathrm{sec}$ \\
\hline$t$ & total volumetric rate & $\mathrm{m}^{3} / \mathrm{sec}$ \\
\hline$i$ & inner radius $m$ ro outer radius & $\mathbf{m}$ \\
\hline 0 & temperature of liquid in proc. tube & ${ }^{\circ} \mathrm{C}$ \\
\hline$t_{g}$ & temperature of gas in gas-lift annulus & ${ }^{\circ} \mathrm{C}$ \\
\hline$v$ & velocity & $\mathrm{m} / \mathrm{sec}$ \\
\hline$v_{s g}$ & superficial gas velocity & $\mathrm{m} / \mathrm{sec}$ \\
\hline$v_{s 0}$ & superficial oil velocity & $\mathrm{m} / \mathrm{sec}$ \\
\hline$s L$ & superficial liquid velocity & $\mathrm{m} / \mathrm{sec}$ \\
\hline$m$ & total superficial velocity & $\mathrm{m} / \mathrm{sec}$ \\
\hline$w$ & gas velocity in gas-lift annulus & $\mathrm{m} / \mathrm{sec}$ \\
\hline$w_{t}$ & total mass velocity & $\mathrm{kg} / \mathrm{sec}$ \\
\hline 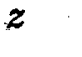 & elevation referred to datum & m \\
\hline$g$ & Z-factor of gas & \\
\hline
\end{tabular}




$\begin{array}{lll}\varepsilon_{p} & \text { paraffin content in fluid } & \mathrm{kg} / \mathrm{m}^{3} \\ \lambda_{g} & \text { gas void fraction (non-slip) } & \\ \lambda_{L} & \text { liquid holdup (non-slip) } & \\ \mu & \text { viscosity } & \text { Pas.sec } \\ \mu_{g} & \text { gas viscosity } & \text { Pas.sec } \\ \mu_{0} & \text { oil viscosity } & \text { Pas.sec } \\ \mu_{L} & \text { effective liquid viscosity } & \text { Pas.sec } \\ \rho & \text { density } & \mathbf{k g} / \mathbf{m}^{3} \\ \rho_{g} & \text { gas density } & \mathbf{k g} / \mathbf{m}^{3} \\ \rho_{O} & \text { oil density } & \mathbf{k g} / \mathbf{m}^{3} \\ \rho_{L} & \text { effective liquid density } & \mathbf{k g} / \mathbf{m}^{3} \\ \rho_{n} & \text { non-slip two-phase density } & \mathbf{k g} / \mathbf{m}^{3} \\ \rho_{m} & \text { two-phase density } & \mathbf{k g} / \mathrm{m}^{3}\end{array}$

\section{Appendix A. Determination of two-phase flow parameters}

The values of quantities in equation (2.1), i.e. the value of function $F_{p_{0}}\left(t_{0}, p_{0}\right)$ can be determined by known methods based on empirical correlations for liquid holdup $H_{L}$ and friction factor $f_{t p}$ such as Beggs and Brills method, Orkiszewski method and Hagerdorn and Brown method [1], [3], [4].

\section{Determination of friction component}

$$
\left(\frac{d p_{0}}{d z}\right)_{f}=\frac{f_{t p} \rho_{f} v_{m f}^{2}}{2 D} f_{c o r r}
$$

- Beggs and Brill method

1. $\rho_{f}=\rho_{n}=\rho_{L} \lambda_{L}+\rho_{g} \lambda_{g}$

2. $f_{t p}=e^{s} f_{n} ; f_{n}=f_{n}\left(N_{R e}\right) ; N_{R e}=\frac{\rho_{n} v_{m} D}{\mu_{n}}$

3. $v_{m f}=v_{s L}+v_{s g}=v_{m}$

4. $f_{\text {corr }}=1.0$

where $s$ is a correlation factor (see [3]).

- Orkiszewski method

* for bubble flow

1. $\rho_{f}=\rho_{L}$

2. $f_{t p}=f_{n} ; f_{n}=f_{n}\left(N_{R e}\right) ; N_{R e}=\frac{\rho_{L} v_{L} D}{\mu_{L}}$

3. $v_{m f}=\frac{q_{L}}{A\left(1-F_{g}\right)}$

4. $f_{\text {corr }}=1.0$

where $F_{g}$ is the void fraction of gas. 
* for slug flow

1. $\rho_{f}=\rho_{L}$

2. $f_{t p}=f_{n} ; f_{n}=f_{n}\left(N_{R e}\right) ; N_{R e}=\frac{\rho_{L} v_{m} D}{\mu_{L}}$

3. $v_{m f}=v_{m}$

4. $f_{\text {corr }}=\frac{q_{L}+v_{b} A}{q_{t}+v_{b} A}+\Gamma$

where $\Gamma$ is the liquid distribution coefficient and $v_{b}$ is the rise-bubble velocity, which can be determined by correlations (see [4]).

* for mist flow

1. $\rho_{f}=\rho_{g}$

2. $f_{t p}=f_{n} ; f_{n}=f_{n}\left(N_{R e}\right) ; N_{R e}=\frac{\rho_{g} v_{s g} D}{\mu_{g}}$

3. $v_{m f}=v_{s g}$

4. $f_{\text {corr }}=1.0$

* transition flow

$$
\left(\frac{d p}{d z}\right)_{f}=S\left[\left(\frac{d p}{d z}\right)_{f}\right]_{s l u g}+M\left[\left(\frac{d p}{d z}\right)_{f}\right]_{m i s t}
$$

where the weighting factors $S, M$ are obtained by correlations (see [4])

- Hagerdorn and Brown method

1. $\rho_{f}=\frac{\rho_{n}^{2}}{\rho_{s m}} ; \rho_{s}=\rho_{L} H_{L}+\rho_{g}\left(1-H_{L}\right)$

2. $f_{t p}=f_{n} ; f_{n}=f_{n}\left(N_{R e}\right) ; N_{R e}=\frac{\rho_{n} v_{m} D}{\mu_{s}} ; \mu_{s}=\left(\mu_{L}\right)^{H_{L}}\left(\mu_{g}\right)^{1-H_{L}}$

3. $v_{m f}=v_{m}$

4. $f_{\text {corr }}=1.0$

2. Determination of elevation component

$$
\left(\frac{d p_{0}}{d z}\right)_{e l}=g \rho_{t p} \sin \theta
$$

- Beggs and Brill method

$$
\rho_{t p}=\rho_{s}
$$

- Orkiszewski method

* for bubble flow

$$
\rho_{t p}=\left(1-F_{g}\right) \rho_{L}+F_{g} \rho_{g}
$$

* for slug flow

$$
\rho_{t p}=\rho_{L}\left(\frac{q_{L}+v_{b} A}{q_{t}+v_{b} A}+\Gamma\right)+\rho_{g}\left(\frac{q_{g}}{q_{t}+v_{b} A}\right)
$$


* for mist flow

$$
\rho_{t p}=\left(1-F_{g}\right) \rho_{L}+F_{g} \rho_{g}
$$

* transition flow

$$
\left(\frac{d p}{d z}\right)_{e l}=S\left[\left(\frac{d p}{d z}\right)_{e l}\right]_{s l u g}+M\left[\left(\frac{d p}{d z}\right)_{e l}\right]_{m i s t}
$$

where the weighting factors $S, M$ are obtained by correlations (see [4])

- Hagerdorn and Brown method

$$
\rho_{t p}=\rho_{s}
$$

3. Determination of acceleration component

$$
\left(\frac{d p_{0}}{d z}\right)_{a c c}=-\frac{\rho_{t p} v_{m} v_{s g}}{p_{0}} \frac{d p_{0}}{d z}
$$

- Beggs and Brill method

$$
\rho_{t p}=\rho_{s}
$$

- Orkiszewski method

$\rho_{t p}$ is determined in the same way as for the elevation component.

- Hagerdorn and Brown method

$$
\left(\frac{d p_{0}}{d z}\right)_{a c c}=0
$$

\section{Appendix B. Determination of overall heat transfer coefficient}

The overall heat transfer coefficient of a fluid in a tube can be a combination of three components. They are convective heat losses between the flowing fluids and the tube wall, conductive losses through the wall and through any insulation or coating material, and conductive losses to the environment. For a buried tube, the overall heat transfer coefficient $U$ can be expressed in the form:

$$
U=\frac{1}{R_{g}+R_{p}+R_{f}}
$$

where $R_{g}=$ resistance to conductive heat transfer from the tube to the ground, $R_{p}=$ resistance to conductive heat transfer through the tube wall and coatings, $R_{f}=$ resistance to convective heat transfer between the flowing fluid and the tube wall. 


\section{For the gas-lift annulus}

$$
k_{\tau g}=\frac{1}{R_{g}+R_{p}+R_{f}}
$$

a. $\quad R_{g}=\frac{f(t)}{2 k_{g} D_{2}}$ where $f(t)$ is a time-dependent, dimensionless function. This function for intervals longer than a week can be expressed as:

$$
f(t)=-\ln \left(\frac{r_{c}}{2 \sqrt{a_{\infty} t}}\right)-0.29
$$

$r_{c}=$ outer radius of casing; $a_{\alpha}=$ thermal diffusivity of the earth; $t=$ time since well began flowing.

b. $\quad R_{f}=\frac{D_{2}}{k_{f g} N u}$ where $N u=0.027 \operatorname{Re}^{0.8} \operatorname{Pr}^{1 / 3}=$ Nusselt number; and Reynold number $R e$ is calculated based on $D_{t e q}$ from (2.7)

c. $R_{p}=\sum R_{p(i)}$ where $R_{p(i)}=\frac{\ln \left(r_{0(i)} / r_{i(i)}\right)}{2 k_{p(i)} / D_{2}}$

2. for the section of producing tube below the injection point (where $\left.z>z_{g l}\right)$

The calculation of $k_{\tau}$ is similar to the case of gas-lift annulus. But the outer diameter $D_{2}$ and the equivalent thermal diameter $D_{\text {teq }}$ of gas-lift annulus must be replaced by the inner diameter $D$ of producing tube.

3. for the section of producing tube above the injection point (where $\left.z<z_{g l}\right)$

$$
k_{\tau}=\frac{1}{R_{g}+R_{p}+R_{f}}
$$

a. $R_{g}=0$

b. $R_{p}=\frac{\ln \left(r_{0} / r_{i}\right)}{2 k_{p} / D}$

c. $R_{f}=R_{f t u g}+R_{f g s l}$

where $R_{f t u b}=$ resistance to convective heat transfer between the flowing fluid and the producing tube wall with $R e$ based on inner diameter of the tube, $R_{f g s l}=$ resistance to convective heat transfer between the flowing injected gas and the producing tube wall with Re based on thermal equivalent diameter.

\section{REFERENCES}

1. Oil and Gas Consultants International Inc. and H. Dale Beggs, Production Optimization Using Nodal Analysis, 1991. 
2. Pudovkin M. A., Calamatin A. H., Tchugunov V. A., Tempetature proceses in producing wells. Kazan, 1977.

3. H. Dale Beggs, James P. Brill, A Study of Two-phase Flow in Inclined Pipe. JPT, 1973.

4. Orkiszewski J., Predicting Two-phase Pressure Drop in Vertical Pipe. JPT, 1967.

5. Donald Q. Kern, Process Heat Transfer. 1965.

6. Joe D. Hoffman, Numerical methods for Engineers and Scientists. 1993.

Received Aprill 20, 1999

MỘT THUẬT TOÁN XÁC ĐỊNH ĐỒNG THỠI PHÂN BỐ ÁP SUÂT VÀ NHIỆT Độ TRONG ỐNG KHAI THÁC DÂU

VÀ TRONG VÀNH KHUYÊN GASLIFT

Bài báo đưa ra một thuật toán xác định đồng thời phân bố áp suất và nhiệt độ dòng cháy trong ống khai thác dầu và dòng chảy ngược của khí trong vành khuyên gaslift. Thuật toán dựa trên quy trình lặp kép và phương pháp “bắn”. Việc tính toán áp suất của dòng chảy hai pha trong thuật toán dựa trên các phương pháp Beggs và Brills, Orkiszewski hoặc phương pháp Hagedorn và Brown đã được cải tiến. Một ví dụ tính toán số được trình bày để chứng tở khá năng áp dụng của thuật toán vào trong thực tế.

* Institute of Mechanics

264 Doi Can, Hanoi, Vietnam

** Institute of Offshore Oil-Gas Research Design, JV Vietsovpetro

95a Leloi, Vung tau, Vietnam 